\title{
Phosphorus and water recovery by a novel osmotic membrane bioreactor-reverse osmosis system
}

\author{
Wenhai Luo ${ }^{a}$, Faisal I. Hai ${ }^{a}$, William E. Price ${ }^{b}$, Wenshan Guo ${ }^{c}$, Hao H. Ngo ${ }^{c}$, Kazuo \\ Yamamoto $^{\mathrm{d}}$, Long D. Nghiem ${ }^{\mathrm{a}, *}$ \\ ${ }^{\text {a }}$ Strategic Water Infrastructure Laboratory, School of Civil, Mining and Environmental Engineering, University \\ of Wollongong, Wollongong, NSW 2522, Australia \\ ${ }^{\mathrm{b}}$ Strategic Water Infrastructure Laboratory, School of Chemistry, University of Wollongong, Wollongong, \\ NSW 2522, Australia \\ ${ }^{\mathrm{c}}$ Centre for Technology in Water and Wastewater, School of Civil and Environmental Engineering, University \\ of Technology Sydney, Sydney, NSW 2007, Australia \\ ${ }^{\mathrm{d}}$ Environmental Science Centre, University of Tokyo, Tokyo 113-0033, Japan
}

\section{Highlights}

- Phosphorus was periodically extracted via MF from the mixed liquor of OMBR-RO.

- Phosphorus was precipitated from the MF permeate as calcium phosphate.

- Recovered precipitate at $\mathrm{pH} 10$ contained $15-20 \%$ phosphorus.

- MF extraction prevented salinity build-up and ensured stable biological performance.

- Contaminant build-up in the draw solution deteriorated RO membrane performance.

\begin{abstract}
An osmotic membrane bioreactor-reverse osmosis (OMBR-RO) hybrid system integrated with periodic microfiltration (MF) extraction was evaluated for simultaneous phosphorus and clean water recovery from raw sewage. In this hybrid system, the forward osmosis membrane effectively retained inorganic salts and phosphate in the bioreactor, while the MF membrane periodically bled them out for phosphorus recovery with $\mathrm{pH}$ adjustment. The RO process was used for draw solute recovery and clean water production. Results show that phosphorus recuperation from the MF permeate was most effective when the solution $\mathrm{pH}$ was adjusted to 10 , whereby the recovered precipitate contained $15-20 \%$ (wt/wt) of phosphorus. Periodic MF extraction also limited salinity build-up in the bioreactor, resulting in a stable biological performance and an increase in water flux during OMBR operation. Despite the build-up of organic matter and ammonia in the draw solution, OMBR-RO allowed for the recovery of high quality reused water.
\end{abstract}

\section{Keywords}

Phosphorus recovery; Osmotic membrane bioreactor (OMBR); Forward osmosis (FO); Reverse osmosis (RO); Microfiltration (MF) 


\section{Introduction}

Phosphorus is a finite resource and an essential nutrient for agriculture production. In the environment, phosphorus is also a contaminant that can result in severe eutrophication of natural waterways (Conley et al., 2009). In addition, during wastewater treatment, phosphorus (in the form of phosphate) can react with ammonium and magnesium to form crystalline precipitate known as struvite, which causes blockage and scaling of plant equipment (Doyle et al., 2002). Thus, phosphorus recovery from wastewater is strategically important to secure a continuous and sustainable supply of this essential nutrient, reduce environmental discharge, and avoid struvite scaling.

The osmotic membrane bioreactor (OMBR) system has been recently recognized as a promising technology in wastewater treatment and reuse (Achilli et al., 2009, Cornelissen et al., 2011, Luo et al., 2014 and Nguyen et al., 2015). OMBR utilizes forward osmosis (FO) to extract treated water from the bioreactor mixed liquor into a draw solution. This system can be used as a stand-alone process to extract treated water for osmotic dilution or integrated with other processes, such as reverse osmosis (RO) or membrane distillation (MD), to produce clean water and recover the draw solute. Compared to conventional MBR systems that employ pressure-driven membrane processes, such as microfiltration (MF) and ultrafiltration (UF), OMBR has several advantages, including higher contaminant removal and lower membrane fouling propensity (Cornelissen et al., 2008, Achilli et al., 2009 and Alturki et al., 2012).

A major technical challenge to OMBR application is the build-up of salinity in the bioreactor (Yap et al., 2012 and Luo et al., 2014). This occurs due to the high salt rejection by the FO membrane and, more importantly, reverse solute flux from the draw solution. The increased bioreactor salinity can severely affect the microbial viability and membrane performance (Nawaz et al., 2013). Thus, several approaches have been recently proposed to prevent salinity build-up in the bioreactor during OMBR operation. A promising control strategy is to integrate an MF or UF membrane with OMBR to form a hybrid MF/UF-OMBR system to bleed out dissolved inorganic salts accumulated in the bioreactor. By applying this strategy, Wang et al. (2014) demonstrated a stable operation of OMBR integrated with continuous MF extraction and concluded that the integration of MF could increase OMBR water flux and improve the biological treatment. Similar observations were subsequently reported by Holloway et al. (2015) who combined an UF membrane with OMBR. 
The hybrid MF/UF-OMBR system has the potential to simultaneously recover phosphorus and clean water during wastewater treatment. In this hybrid system, the FO membrane can effectively retain phosphate and magnesium/calcium based salts in the bioreactor, while the MF/UF membrane allows them to be bled out for phosphorus recovery by $\mathrm{pH}$ adjustment. Based on this rationale, Qiu et al. (2015) showed that phosphorus could be directly recovered from municipal wastewater mostly in the form of calcium phosphate by a hybrid MF-OMBR system, where the FO and MF membranes were operated continuously in parallel. In their study, phosphate concentration in the bioreactor was in the range of $10-70 \mathrm{mg} / \mathrm{L}$ over 98 days of operation and decreased with an increase in the MF permeate flux (Qiu et al., 2015). It is noteworthy that phosphate enrichment in the bioreactor can be further enhanced by operating the MF membrane at low permeate flux or in periodic extraction mode, thereby increasing the economics of phosphorus recovery from the OMBR mixed liquor, preventing the hydraulically pressure-driven MF membrane from fouling, and reducing its energy consumption.

This study aimed to investigate the potential of a hybrid OMBR-RO system integrated with periodic MF extraction to simultaneously recover phosphorus and clean water from raw sewage. The RO process was used for draw solute recovery and clean water production. Phosphorus was directly recovered from the MF permeate, extracted periodically from the OMBR mixed liquor, in the form of phosphorus precipitates by $\mathrm{pH}$ adjustment. Performance of the hybrid OMBR-RO system was systematically assessed in terms of water production, product water quality, membrane fouling, and biological stability.

\section{Methods}

\subsection{Wastewater and membranes}

Raw sewage was collected from the Wollongong Wastewater Treatment Plant (New South Wales, Australia) and stored at $4{ }^{\circ} \mathrm{C}$. Over the experimental period of 60 days, 18 measurements were conducted to determine key water quality parameters of this sewage. The composition of raw sewage was relatively stable. The concentrations of orthophosphate, ammonia, calcium, magnesium, and potassium were $24 \pm 4,45 \pm 4,23 \pm 5,33 \pm 3$ and $15 \pm 1 \mathrm{mg} / \mathrm{L}$, respectively (average \pm standard deviation). Conductivity, $\mathrm{pH}$, and total organic carbon concentration of this sewage were $1130 \pm 53 \mu \mathrm{S} / \mathrm{cm}, 7.3 \pm 0.2$, and $28 \pm 5 \mathrm{mg} / \mathrm{L}$, respectively (average \pm standard deviation). 
A flat-sheet, cellulose-based FO membrane from Hydration Technology Innovations (Albany, OR) was used for the OMBR process. The FO membrane comprised a cellulose triacetate layer embedded with a polyester mesh for mechanical support. A flat-sheet, ESPA2 membrane supplied by Hydranautics (Oceanside, CA) was used for the RO process. The RO membrane was composed of a thin polyamide layer with a porous polysulfone support layer.

A hollow fiber MF membrane module (Mitsubishi Rayon Engineering, Tokyo, Japan) was also used in this study. The MF membrane was made of polyvinylidene fluoride. The effective surface area and nominal pore size of this membrane module were $740 \mathrm{~cm}^{2}$ and $0.4 \mu \mathrm{m}$, respectively.

\subsection{OMBR-RO system and operation}

The lab-scale OMBR-RO hybrid system used in this study comprised a feed reservoir, an aerobic bioreactor, and a submerged FO and a cross-flow RO unit (Fig. 1). A Masterflex peristaltic pump (Cole-Parmer, Vernon Hills, IL) controlled by a water level sensor was used to feed the bioreactor with an effective volume of $6 \mathrm{~L}$. The feed reservoir was placed on a digital balance (Mettler-Toledo, Hightstown, IL) connected to a computer to determine the OMBR water flux.

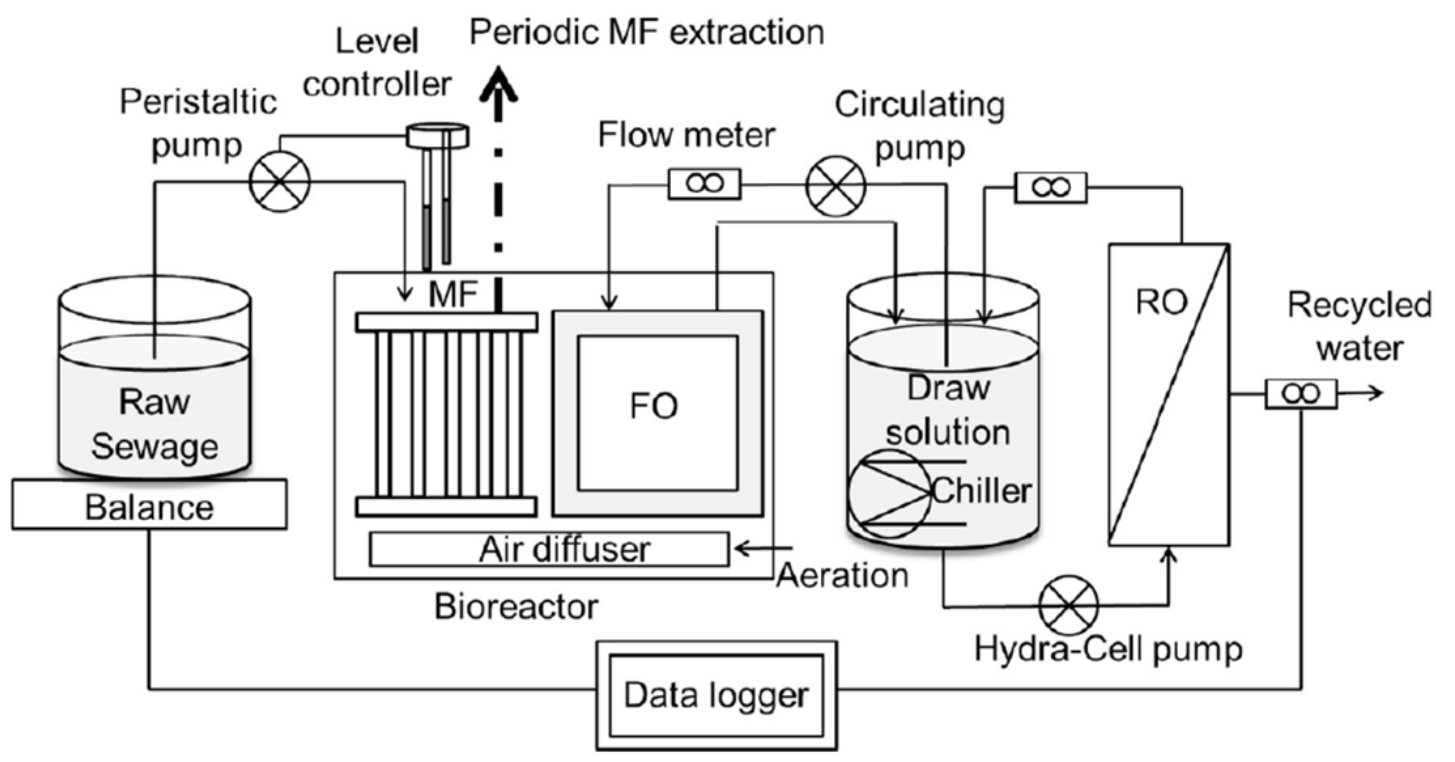

Fig. 1. Schematic diagram of a lab-scale OMBR-RO hybrid system integrated with periodic MF extraction. 
The FO component comprised a submerged, plate-and-frame membrane cell, a gear pump (Micropump, Vancouver, WA), and a stainless steel draw solution reservoir with a working volume of $8 \mathrm{~L}$. The membrane cell was made of acrylic plastic with a draw solution flow channel $20 \mathrm{~cm}$ long, $15 \mathrm{~cm}$ wide, and $0.4 \mathrm{~cm}$ high. The FO membrane was mounted on the cell with the support layer in contact with the draw solution (i.e. FO mode). A $0.5 \mathrm{M} \mathrm{NaCl}$ draw solution (corresponding to osmotic pressure of 23 bar determined by the OLI Stream Analyzer software) was circulated from the draw solution reservoir to the membrane cell at a cross-flow velocity of $2.8 \mathrm{~cm} / \mathrm{s}$.

The RO process was used to recover the draw solute and extract clean water. A Hydra-Cell pump (Wanner Engineering, Minneapolis, MN) was used to feed the draw solution to a stainless steel RO membrane cell, which had a flow channel $10 \mathrm{~cm}$ long, $4 \mathrm{~cm}$ wide and $0.2 \mathrm{~cm}$ deep. The hydraulic pressure and retentate cross-flow velocity were regulated by a back-pressure regulator and a bypass valve. A digital flow meter (Optiflow, Palo Alto, CA) was connected to a computer to monitor the permeate flux. The draw solution temperature was maintained at $22 \pm 1{ }^{\circ} \mathrm{C}$ by a temperature control unit (Neslab RTE7, Waltham, MA) equipped with a stainless steel heat exchanger coil.

Prior to the OMBR-RO operation, activated sludge collected from the Wollongong Wastewater Treatment Plant (New South Wales, Australia) was seeded to the bioreactor integrated with an MF membrane module to form a standard MBR to pre-condition the biomass under laboratory conditions. Once acclimatized in terms of the bulk organic removal (i.e. $95 \%$ total organic carbon (TOC) removal), the MF module was replaced by the FO module and the RO unit was integrated to form the hybrid OMBR-RO system.

The hybrid OMBR-RO system was run for 60 days in a temperature-controlled room $\left(22 \pm 1^{\circ} \mathrm{C}\right)$, following a cycle of 8 days 'on' (continuous operation) and 2 days 'off' (cease of feeding and FO-RO extraction). The MF membrane was operated to extract water from the bioreactor mixed liquor for subsequent phosphorus recovery when the FO and RO membranes were kept 'off' (Section 2.3). The initial mixed liquor suspended solids (MLSS) concentration was adjusted to approximately $10 \mathrm{~g} / \mathrm{L}$. The sludge retention time (SRT) was maintained at 50 days by regularly wasting a small amount of mixed liquor every two days. The hydraulic retention time (HRT) was determined by the OMBR water flux and was in the range of $30-80 \mathrm{~h}$. The mixed liquor $\mathrm{pH}$ was maintained between 6 and 7 by periodically dosing small volumes of concentrated $\mathrm{HCl}$ solution to reduce the spontaneous precipitation of phosphate minerals in the bioreactor. The bioreactor was continuously aerated to obtain 
dissolved oxygen (DO) concentration of approximately $5 \mathrm{mg} / \mathrm{L}$ throughout the experiment. The RO permeate flux was adjusted daily to match that from the OMBR by regulating the hydraulic pressure while maintaining the retentate cross-flow velocity at $41.7 \mathrm{~cm} / \mathrm{s}$. On day 30 of the experiment, $50 \mathrm{~g} \mathrm{NaCl}$ was added to the draw solution to compensate for the draw solute loss. This value was calculated based on the reduction in the concentration of the draw solution (due to reverse draw solute flux and its permeation through the RO membrane), which was determined by its electrical conductivity and a $\mathrm{NaCl}$ calibration curve.

\subsection{Phosphorus recovery protocol}

During OMBR-RO off time, the MF membrane was operated for 24 hours to extract $3 \mathrm{~L}$ water (i.e. $50 \%$ water recovery) from the bioreactor mixed liquor at a constant permeate flux of $1.7 \mathrm{~L} / \mathrm{m}^{2} \mathrm{~h}$. The bioreactor mixed liquor was subsequently replenished with $3 \mathrm{~L}$ sewage and aerated for $24 \mathrm{~h}$ before a new OMBR-RO operating recycle. Periodic MF extraction was employed here to ensure high phosphate enrichment in the bioreactor during OMBR-RO operation, thereby increasing the efficiency of subsequent phosphorus recovery. In addition, the intermittent operation mode could also reduce the MF membrane fouling and energy consumption.

Phosphorus in the MF permeate was directly recovered by $\mathrm{pH}$ adjustment using a $3 \mathrm{M} \mathrm{NaOH}$ solution. The MF permeate extracted after the first 8 days of OMBR-RO operation (denoted as "MF-1") was used to evaluate the efficiency of phosphorus recovery as a function of $\mathrm{pH}$ (between $\mathrm{pH} 8$ and 13). The optimal $\mathrm{pH}$ was applied to recover phosphorus from the MF permeate extracted in the subsequent OMBR-RO operating cycles. The pH-adjusted permeate was gently mixed using a magnetic stirrer, and then filtered through $0.7 \mu \mathrm{m}$ glass fiber filters to recover precipitates. Recovered solids were air-dried in a desiccator at room temperature $\left(22 \pm 1{ }^{\circ} \mathrm{C}\right)$ and filtrates were stored at $4{ }^{\circ} \mathrm{C}$ for subsequent analysis.

\subsection{Analytical methods}

\subsubsection{Water quality analysis}

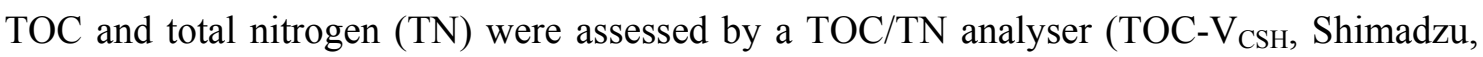
Kyoto, Japan). Ammonium $\left(\mathrm{NH}_{4}{ }^{+}-\mathrm{N}\right)$ and orthophosphate $\left(\mathrm{PO}_{4}{ }^{3-}-\mathrm{P}\right)$ ions were measured using a Flow Injection Analysis system (QuikChem 8500, Lachat, CO). Calcium $\left(\mathrm{Ca}^{2+}\right)$, magnesium $\left(\mathrm{Mg}^{2+}\right)$, and potassium $\left(\mathrm{K}^{+}\right)$ions were determined using an inductively coupled 
plasma-optical emission spectrometer (710 ICP-OES, Agilent Technologies, CA). Solution $\mathrm{pH}$ and conductivity were measured using an Orion 4-Star Plus $\mathrm{pH} /$ conductivity meter (Thermo Scientific, Waltham, MA).

\subsubsection{Precipitate characterization}

Precipitates obtained were air-dried and characterized using X-ray diffraction (GBC MMA, Hampshire, IL). The morphology and elemental composition of precipitates were examined using a scanning electron microscopy (SEM) coupled to energy dispersive spectroscopy (EDS) (JEOL JCM-6000, Tokyo, Japan). In addition, the dried precipitates were dissolved with 5\% nitric acid to determine major elemental concentrations using ICP-OES.

\subsubsection{Membrane autopsy}

At the conclusion of the experiment, the surface morphology of both $\mathrm{FO}$ and $\mathrm{RO}$ membranes was analyzed by SEM-EDS. Prior to SEM measurement, membrane samples were air-dried in a desiccator and then coated with an ultra-thin layer of gold using a sputter coater (SPI Module, West Chester, PA).

\subsubsection{Biomass characterization}

MLSS and mixed liquor volatile suspended solids (MLVSS) concentrations were measured following the Standard Method 2540. Biomass activity was assessed by measuring the specific oxygen uptake rate (SOUR) of the activated sludge based on the Standard Method 1683. Extracellular polymeric substances (EPS) and soluble microbial products (SMP) in the mixed liquor were quantified by measuring the protein and polysaccharide concentrations. EPS was extracted using a thermal method previously reported by Zhang et al. (1999). Protein concentration was measured by the Folin method using bovine serum albumin as the

standard (Lowry et al., 1951). Polysaccharide concentration was determined using the phenol-sulfuric acid method with a glucose standard (Dubois et al., 1956).

\section{Results and discussion}

\subsection{Bioreactor salinity and phosphate enrichment}

During OMBR operation, reverse solute $(\mathrm{NaCl})$ flux from the draw solution and high salt rejection by the FO membrane resulted in an increase in the mixed liquor conductivity 
(Fig. 2a). By periodically bleeding out dissolved salts via the MF membrane, salinity build-up in the bioreactor could be effectively controlled. During the entire experiment, the mixed liquor conductivity was in the range of $7-14 \mathrm{mS} / \mathrm{cm}$ (corresponding to approximately 3.5 and $7 \mathrm{~g} / \mathrm{L} \mathrm{NaCl}$, respectively). This salinity range is higher than that reported in previous studies where a stable mixed liquor conductivity of approximately $5 \mathrm{mS} / \mathrm{cm}$ was observed during OMBR operation with continuous MF extraction (Wang et al., 2014 and Qiu et al., 2015). Nevertheless, following a small and brief disturbance at the beginning of the experiment (Section 3.3), stable biological performance could be obtained. The observed stable operation can be attributed to the acclimatization of the biomass in the activated sludge to the saline condition (Lay et al., 2010 and Jang et al., 2013).

FO membrane rejection resulted in the enrichment of $\mathrm{Ca}^{2+}, \mathrm{Mg}^{2+}, \mathrm{K}^{+}$, and $\mathrm{PO}_{4}{ }^{3-}-\mathrm{P}$ in the bioreactor (Fig. 2b). High concentrations of these cations may induce spontaneous phosphate precipitation in the bioreactor, particularly under alkaline conditions (Qiu and Ting, 2014), thereby reducing soluble phosphate ions extractable by the MF membrane for subsequent recovery. For example, Chen et al. (2014) observed an initial increase but then a subsequent decrease in phosphorus concentration in an anaerobic OMBR when the mixed liquor $\mathrm{pH}$ increased from 6.9 to 7.6. In their study, the $\mathrm{pH}$ increase was driven by forward proton diffusion from the bioreactor to the draw solution associated with reverse draw solute flux to maintain the mixed liquor electro-neutrality (Hancock and Cath, 2009). Thus, in this study, to reduce spontaneous phosphate precipitation in the bioreactor, the mixed liquor $\mathrm{pH}$ was maintained between 6 and 7 by periodically adding small amounts of concentrated $\mathrm{HCl}$ solution. Although a lower mixed liquor $\mathrm{pH}$ could maximize dissolved phosphate ions in the bioreactor for subsequent MF extraction (Qiu et al., 2015), it may adversely affect the microbial viability (Tadkaew et al., 2010) and the FO membrane performance (Xie et al., 2012). 

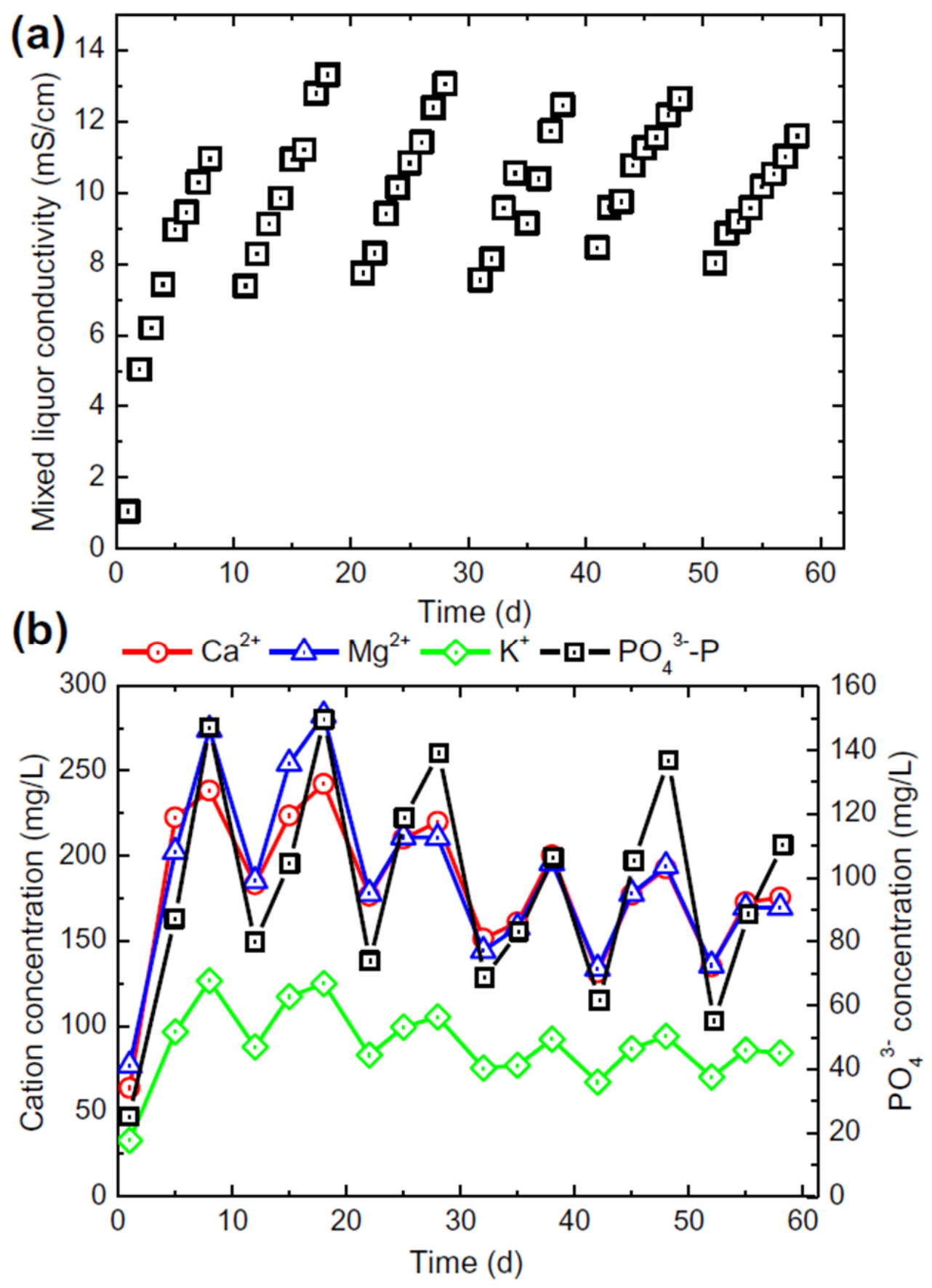

Fig. 2. (a) Mixed liquor conductivity and (b) major cation and $\mathrm{PO}_{4}{ }^{3-}-\mathrm{P}$ concentrations in the bioreactor. OMBR-RO was run in a cycle of $8 \mathrm{~d}$ on and $2 \mathrm{~d}$ off. MF was operated for $24 \mathrm{~h}$ to extract $3 \mathrm{~L}$ water from the bioreactor for phosphorus recovery during OMBR-RO off time. The bioreactor was then replenished with $3 \mathrm{~L}$ sewage and aerated for $24 \mathrm{~h}$. On day 30, $50 \mathrm{~g}$ $\mathrm{NaCl}$ was added to the draw solution. Experimental conditions: draw solution $=0.5 \mathrm{M} \mathrm{NaCl}$; cross-flow velocity $=2.8 \mathrm{~cm} / \mathrm{s}$; initial MLSS concentration $=10 \mathrm{~g} / \mathrm{L}$; mixed liquor $\mathrm{pH}=6-7$; $\mathrm{SRT}=50 \mathrm{~d} ; \mathrm{HRT}=30-80 \mathrm{~h} ; \mathrm{DO}=5 \mathrm{mg} / \mathrm{L}$; temperature $=22 \pm 1{ }^{\circ} \mathrm{C}$. 


\subsection{Phosphorous recovery from the MF permeate}

Dissolved inorganic salts and phosphate enriched in the bioreactor during OMBR operation were readily permeable through the MF membrane (Fig. 2b). Inorganic salts may facilitate phosphorus recovery by enhancing ionic strength and precipitation potentials (Song et al., 2002). Therefore, phosphorus in the MF permeate could be directly captured in the form of phosphate minerals by $\mathrm{pH}$ adjustment without any inorganic salt addition.

\subsection{1. $\mathrm{pH}$ adjustment of the MF permeate}

By increasing the MF permeate $\mathrm{pH}$, phosphorus precipitate could be obtained. As shown in Fig. 3, soluble $\mathrm{Ca}^{2+}$ and $\mathrm{PO}_{4}{ }^{3-}-\mathrm{P}$ in the MF permeate decreased considerably when $\mathrm{pH}$ increased from 8 to 10 . The increase in $\mathrm{pH}$ resulted in the deprotonation of phosphate species (i.e. from $\mathrm{H}_{2} \mathrm{PO}_{4}{ }^{-}$to $\mathrm{HPO}_{4}{ }^{2-}$ and then $\mathrm{PO}_{4}{ }^{3-}$ ) and thus enhanced their reactivity as inorganic ligands or ion pairs with calcium (Reddy and DeLaune, 2008). Elemental analysis also revealed an increase in calcium and phosphorus contents in the recovered precipitate as the MF permeate $\mathrm{pH}$ increased from 8 to 10 . Further $\mathrm{pH}$ increase from 10 to 13 resulted in nearly complete capture of $\mathrm{PO}_{4}{ }^{3-}-\mathrm{P}$ from the MF permeate (Fig. 3). At the same time, the high $\mathrm{pH}$ also induce the formation of other calcium/magnesium-based precipitates without phosphorus, as indicated by the significant decline in soluble $\mathrm{Ca}^{2+}$ and $\mathrm{Mg}^{2+}$ in the $\mathrm{MF}$ permeate at $\mathrm{pH}$ above 10. As a result, phosphorus content in the obtained precipitate decreased when $\mathrm{pH}$ increased from 10 to 13 . Thus, a solution $\mathrm{pH}$ of up to 10 would assist in maximizing phosphorus content in the recovered precipitate from the MF permeate. This result is consistent with that previously reported by Song et al. (2002) who modeled that an increase in solution $\mathrm{pH}$ up to 10 significantly promoted phosphorus recovery by the precipitation of calcium phosphate.

Both $\mathrm{NH}_{4}{ }^{+}-\mathrm{N}$ and $\mathrm{K}^{+}$can react with $\mathrm{Mg}^{2+}$ and $\mathrm{PO}_{4}{ }^{3-}-\mathrm{P}$ to form struvite or its analogs for

phosphorus recovery ( $\mathrm{Xu}$ et al., 2011). In this study, despite the high $\mathrm{Mg}^{2+}$ and $\mathrm{PO}_{4}{ }^{3-}-\mathrm{P}$ concentrations, no significant decrease in either $\mathrm{NH}_{4}{ }^{+}-\mathrm{N}$ or $\mathrm{K}^{+}$concentrations was observed in the MF permeate after recovering the precipitate at $\mathrm{pH}$ of 8-13 (Fig. 3). This observation suggests that the crystallization of struvite and its analogs was not a major pathway for phosphorus recovery. Indeed, as shown in the next section, the obtained phosphorus was mostly in the form of amorphous calcium phosphates. 


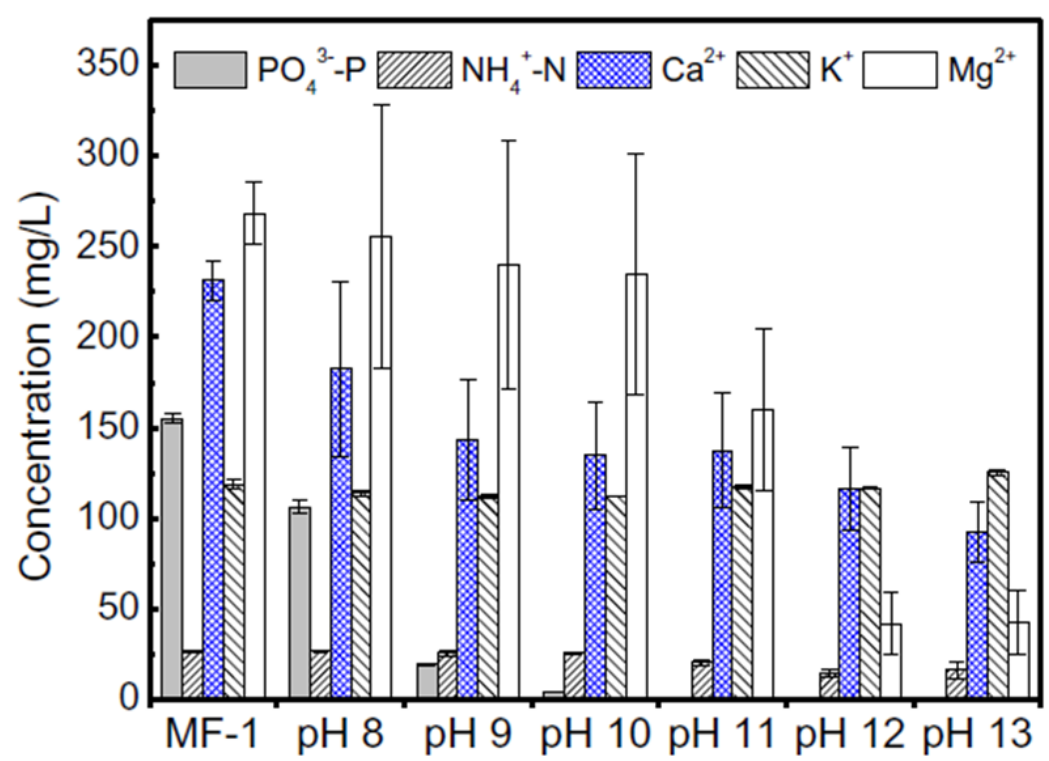

Fig. 3. Orthophosphate, ammonium, and major cation concentrations in MF-1 permeate before and after phosphorus recovery by $\mathrm{pH}$ adjustment. MF-1 permeate was extracted from OMBR mixed liquor in the first operating cycle. MF permeate $\mathrm{pH}$ was adjusted using $3 \mathrm{M}$ $\mathrm{NaOH}$ solution and then gently mixed, followed by filtering through $0.7 \mu \mathrm{m}$ glass fiber filters. Error bars represent standard deviation from duplicate measurements.

\subsubsection{Precipitate composition and characteristics}

The precipitate recovered from the MF permeate at $\mathrm{pH} 10$ was characterized to identify the solid morphology, elemental composition, and structure. The recovered precipitate demonstrated a distinctive amorphous structure. The EDS spectrum of the recovered solids showed that the three major peaks were oxygen, phosphorus, and calcium, which are key elements of calcium phosphate. In addition, a low nevertheless discernible peak was also detected for carbon, sodium, magnesium, silicon, chloride, and potassium, possibly due to their considerable accumulation in the bioreactor during OMBR operation. The XRD spectrum showed a broad peak between the diffusion angles of $25^{\circ}$ and $35^{\circ}$, suggesting that the obtained precipitate was mostly amorphous calcium phosphates (Cao and Harris, 2008), rather than the more thermodynamically stable hydroxyapatite. This observation is consistent with that reported by Qiu et al. (2015) who attributed it to the high activation energy required for hydroxyapatite formation. In addition, the presence of $\mathrm{Mg}^{2+}$ and organic matter (e.g. humic-like substances) could inhibit the conversion of amorphous calcium phosphate to hydroxyapatite (Alvarez et al., 2004 and Cao and Harris, 2008). 


\subsubsection{Phosphorus recovery}

Phosphorus content in the precipitates obtained from the MF permeate at $\mathrm{pH} 10$ was in the range of $15-20 \%$ throughout the experiment (Fig. 4). This range is higher than that previously reported (11-13\%) by Qiu et al. (2015), possibly due to a more significant phosphate enrichment in the bioreactor with periodic MF extraction and a higher operational $\mathrm{pH}$ ( $\mathrm{pH} 10$ versus 9). The calcium/phosphorus molar ratio in the recovered precipitate was in the range of $0.9-1.4$, which was slightly lower than the theoretical ratio (1.5) of amorphous calcium phosphate. This result could be attributed to the co-precipitation of amorphous magnesium phosphate, as evidenced by the high magnesium content (12-17\%) in the precipitate (Fig. 4). Nevertheless, beneficial reuse or environmental discharge of the MF permeate after phosphorus recovery must be carefully considered given its high salinity and $\mathrm{pH}$. A potential strategy is to blend it with the RO permeate.

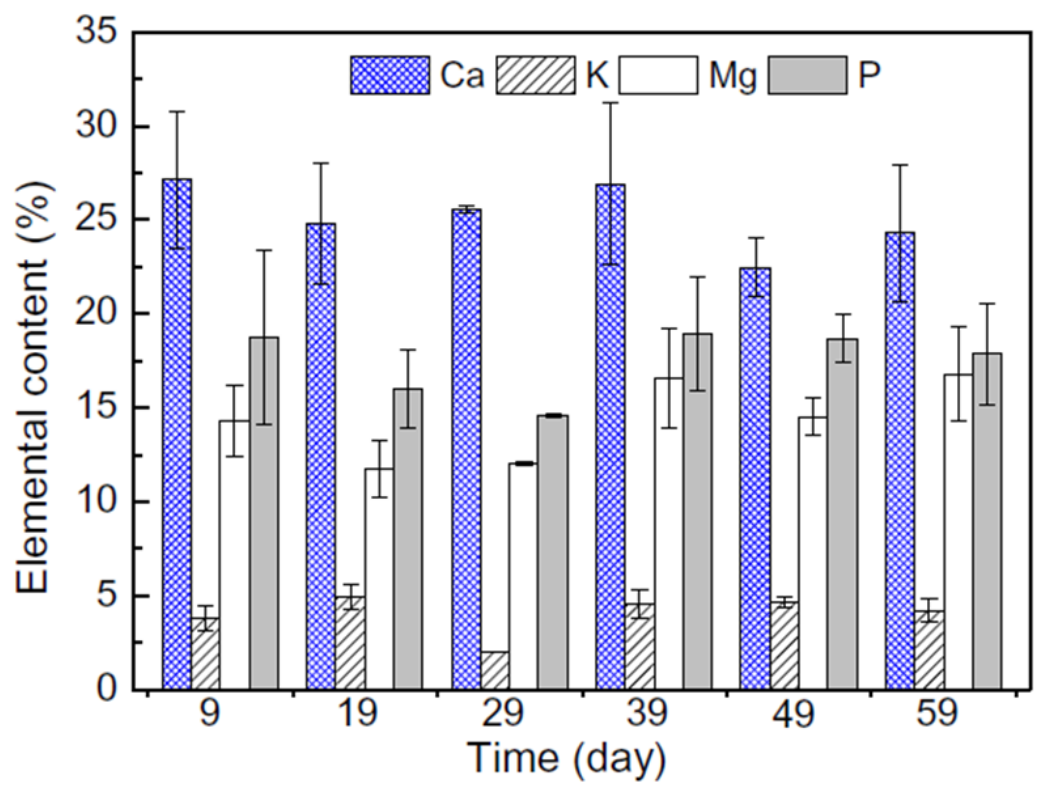

Fig. 4. Major elements in the precipitate recovered from the MF permeate (extracted periodically from OMBR mixed liquor) at $\mathrm{pH} 10$. Error bars represent standard deviation from duplicate measurements.

\subsection{OMBR-RO performance}

\subsubsection{Water production and membrane fouling}

A small and steady water flux decline was observed during OMBR operation (Fig. 5). The observed flux decline can be attributed to membrane fouling, salinity build-up in the bioreactor (Fig. 2a), and a decrease in the draw solution concentration. The last two factors 
could lower the overall driving force (i.e. osmotic pressure difference) for water transport. Thus, a reduction in bioreactor salinity due to periodic MF extraction and subsequent wastewater replenishment increased the water flux of OMBR at the beginning of each operating cycle (Fig. 5).

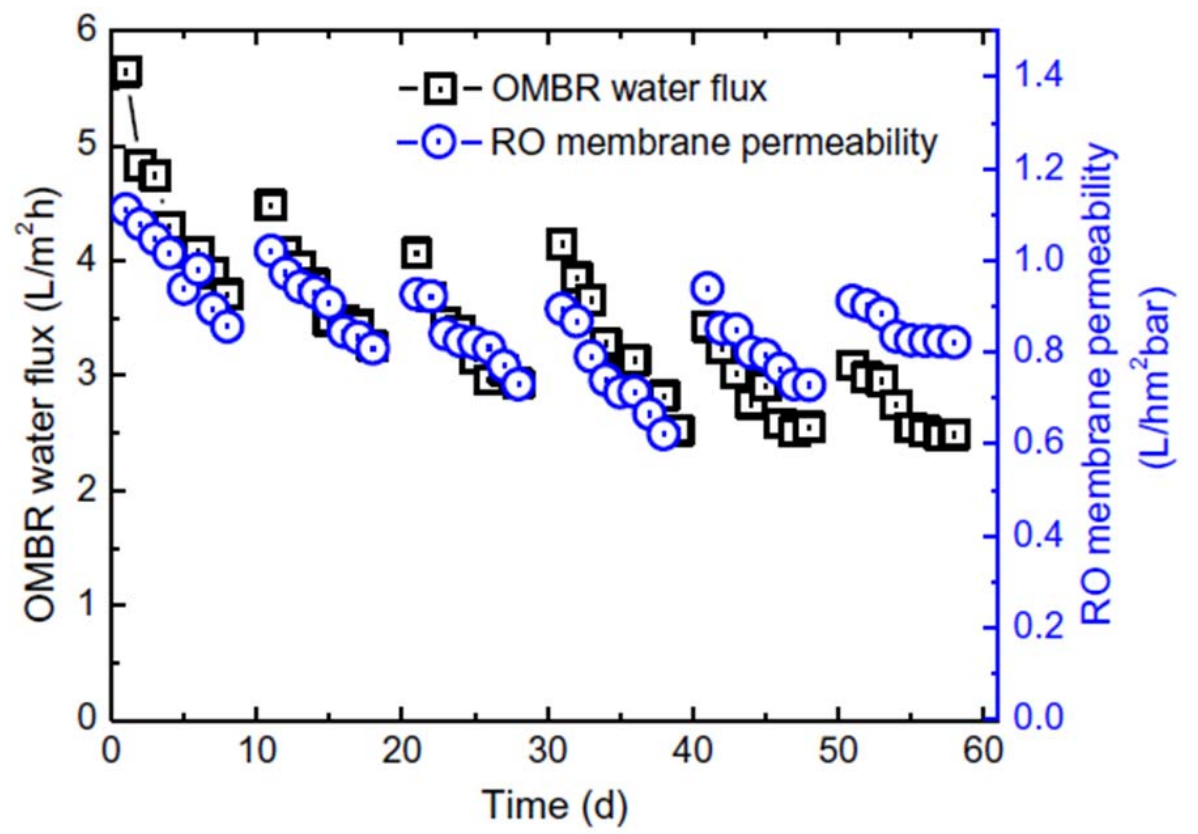

Fig. 5. OMBR water flux and RO membrane permeability over time. Operational protocol and conditions of OMBR-RO are as detailed in the caption of Fig. 1. RO permeate flux was adjusted daily to match that from OMBR by changing the hydraulic pressure while maintaining the retentate cross-flow velocity at $41.7 \mathrm{~cm} / \mathrm{s}$.

Reverse draw solute $(\mathrm{NaCl})$ flux and to a lesser extent its permeation through the $\mathrm{RO}$ membrane (rejection $>98 \%$ ) resulted in a decrease in the draw solution concentration. As noted in Section 2.2, $50 \mathrm{~g} \mathrm{NaCl}$ was added on day 30 to replenish the draw solute loss. However, $\mathrm{NaCl}$ replenishment did not significantly enhance the OMBR water flux compared to that obtained from the previous cycle (Fig. 5). In addition, the role of bioreactor salinity reduction in flux increase was less significant from day 30 onward. These observations indicate that membrane fouling gradually played a much more important role in OMBR flux decline as the experiment progressed. The FO membrane autopsy at the conclusion of the experiment suggests the formation of cake layer, which was mainly composed of carbon, oxygen, sodium, phosphorus, calcium, aluminum, and iron. 
RO membrane permeability exhibited a similar profile to the OMBR water flux over the entire experiment (Fig. 5). The RO membrane permeability decreased gradually due to membrane fouling caused by contaminant accumulation in the draw solution (Fig. 6). A notable increase in the RO membrane permeability was observed at the beginning of each operating cycle (Fig. 5), likely due to fouling mitigation by membrane relaxation when the RO filtration was ceased.

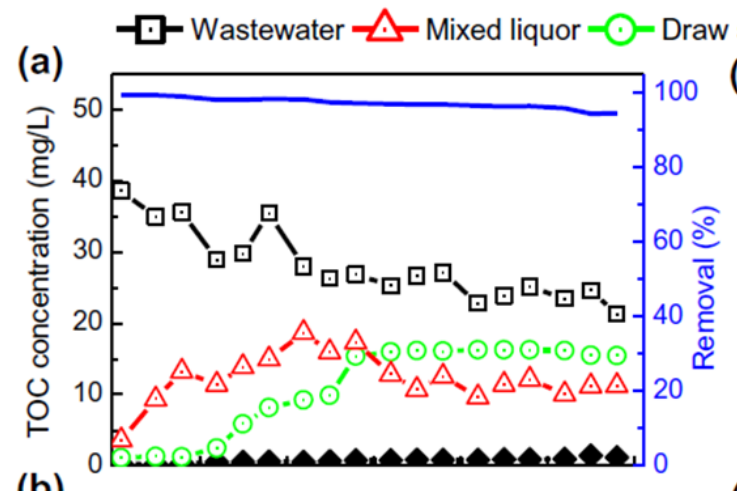

(b)
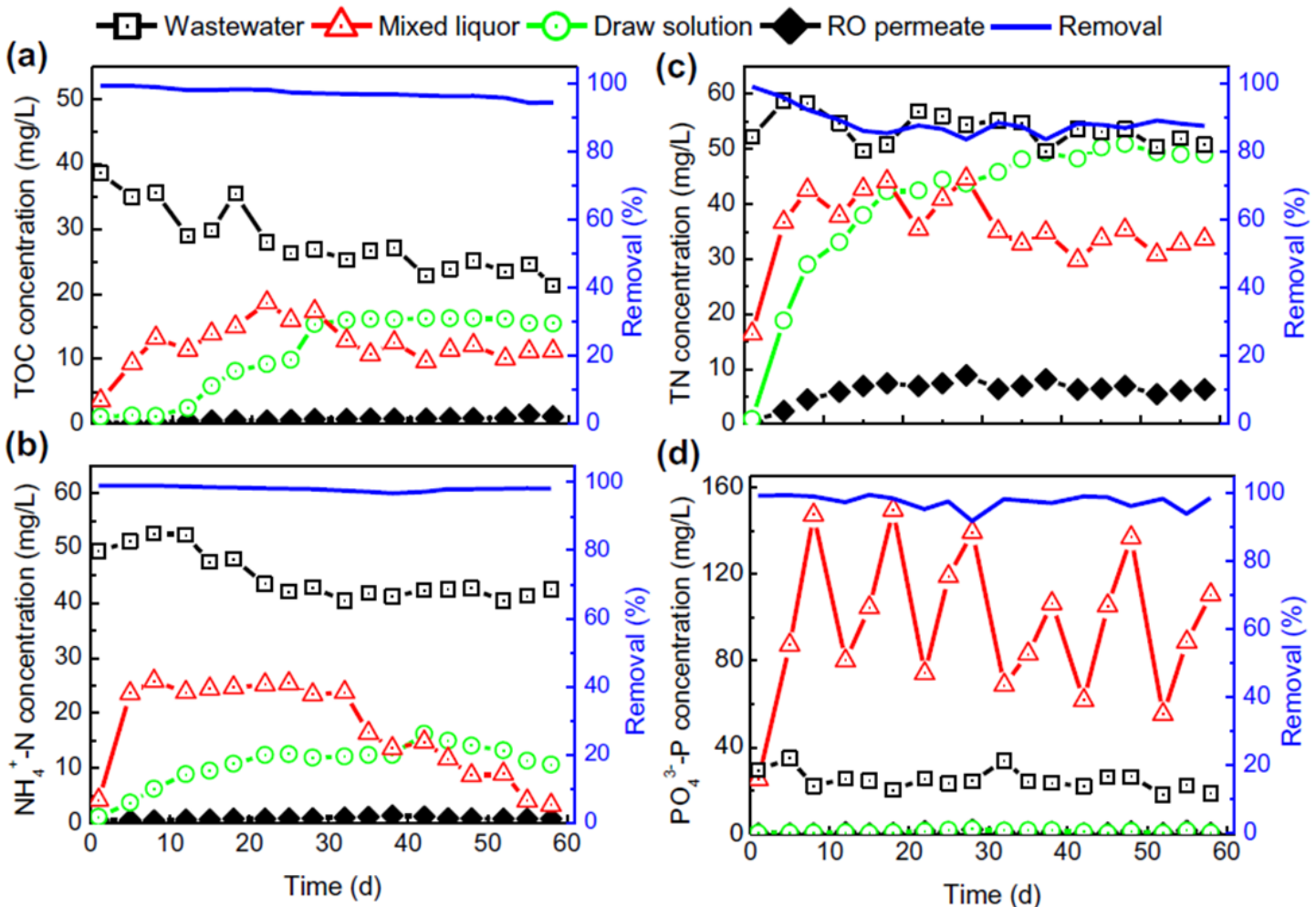

(d)

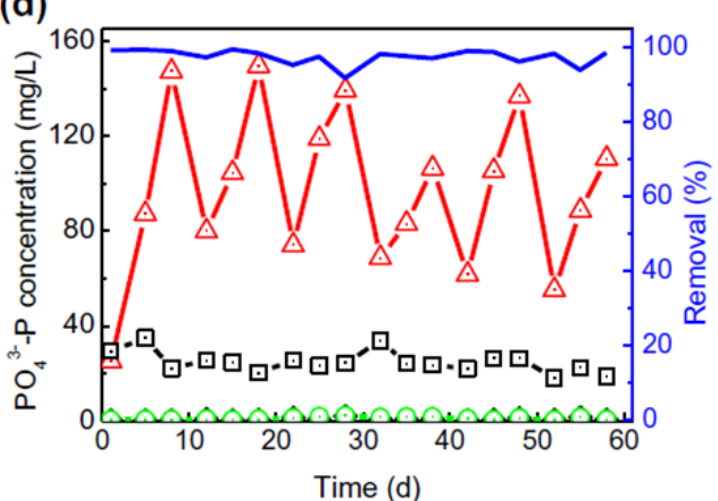

Fig. 6. (a) $\mathrm{TOC}$, (b) $\mathrm{NH}_{4}{ }^{+}-\mathrm{N}$, (c) $\mathrm{TN}$, and (d) $\mathrm{PO}_{4}{ }^{3-}-\mathrm{P}$ concentrations and their overall removal by the hybrid OMBR-RO system. Experimental conditions are as described in the caption of Fig. 1.

\subsubsection{Removal of organic matter and nutrients}

In the OMBR-RO hybrid system, the synergy between biological treatment and highretention membrane processes (i.e. FO and RO) secured the production of high quality recycled water (Fig. 6). During OMBR operation, TOC concentration in the bioreactor increased within the first 30 days (Fig. 6a). This observation could be attributed to the adverse impacts of the elevated bioreactor salinity and the high rejection of organic matter by the FO membrane. The high bioreactor salinity could severely affect the microbial metabolism and thus limit the biological treatment (Lay et al., 2010). As the experiment 
progressed, TOC concentration in the bioreactor gradually decreased and then stabilized at approximately $10 \mathrm{mg} / \mathrm{L}$ from day 35 onward, probably due to microbial adaption to saline conditions (Jang et al., 2013).

The elevated bioreactor salinity also inhibited the nitrification process, thus increasing $\mathrm{NH}_{4}^{+}{ }_{-}^{-}$ $\mathrm{N}$ concentration in the bioreactor (Fig. 6b). In aerobic bioreactors, the nitrification process drives the conversion of $\mathrm{NH}_{4}{ }^{+}-\mathrm{N}$ to $\mathrm{NO}_{2}{ }^{-} \mathrm{N}$ and then $\mathrm{NO}_{3}{ }^{-} \mathrm{N}$. These nitrogen species have been reported to be effectively retained by FO (Holloway et al., 2007 and Cath et al., 2010). As a result, the incomplete nitrification process under a highly saline condition induced the build-up of $\mathrm{NH}_{4}{ }^{+}-\mathrm{N}$ and $\mathrm{NO}_{x}{ }^{-} \mathrm{N}$ in the bioreactor, thereby increasing $\mathrm{TN}$ concentration (Fig. 6c). Nevertheless, both $\mathrm{NH}_{4}{ }^{+}-\mathrm{N}$ and $\mathrm{TN}$ concentrations in the bioreactor gradually decreased from day 30 onward. Once again, this observation could be ascribed to microbial acclimatization to the saline environment of the bioreactor.

Biological phosphorus removal in the aerobic bioreactors occurs mainly through microbial assimilation, particularly by polyphosphate accumulating organisms (Zuthi et al., 2013). These organisms are susceptible to saline conditions, and the increased osmotic pressure within their cells due to salt accumulation could diminish their phosphate accumulating capacity (Lay et al., 2010). Thus, phosphorus removal in OMBR relies largely on the physical rejection by the FO membrane (Yap et al., 2012). In this study, a considerable build-up of $\mathrm{PO}_{4}{ }^{3-}-\mathrm{P}$ in the bioreactor was observed, but its concentration in both the draw solution and the product water (i.e. RO permeate) was negligible (Fig. 6d). Holloway et al. (2007) also showed that near complete rejection of phosphate by an FO membrane could be attained during concentration of anaerobically digested sludge centrate. The high phosphate rejection by FO membranes can be ascribed to the negative charge and large hydrated radius of hydrogen phosphate and dihydrogen phosphate ions, which are the dominant phosphate species in the pH range of 5-10 (Holloway et al., 2007 and Reddy and DeLaune, 2008).

A notable build-up of organic matters (indicated by elevated concentrations of TOC, TN, and $\mathrm{NH}_{4}{ }^{+}-\mathrm{N}$ ) in the draw solution was observed as the experiment progressed (Fig. 6). It has been previously reported that contaminants that were permeable through the FO but not the RO membrane could accumulate in the draw solution and subsequently reduce the product water quality in closed-loop FO-RO hybrid systems (Cath et al., 2010 and D'Haese et al., 2013). In this study, a small but discernible decrease in the overall removal of organic matter and $\mathrm{NH}_{4}{ }^{+}-\mathrm{N}$ by the hybrid OMBR-RO system was observed (Fig. 6). In addition, as discussed above, contaminant accumulation in the draw solution also reduced the permeability of the 
RO membrane (Fig. 5). Therefore, an additional process (e.g. granular activated carbon adsorption) should be implemented to minimize contaminant build-up in the draw solution (Xie et al., 2013), to secure the product water quality in the hybrid OMBR-RO system and enhance the system sustainability in practical applications.

\subsubsection{Biomass characteristics}

Water extraction by the MF membrane from OMBR mixed liquor for phosphorus recovery did not significantly impact biomass characteristics (Table 1). The MLSS and MLVSS concentrations in the bioreactor decreased within the first 28 days. A similar decrease over time was also observed for the sludge SOUR value. These observations were likely due to the inhibition on the biological growth and activity caused by the elevated bioreactor salinity (Reid et al., 2006 and Lay et al., 2010). Nevertheless, stable biomass concentration and sludge SOUR value were observed from day 28 onward due to microbial adaptation to the saline bioreactor condition.

Table 1. Biomass characteristics during OMBR-RO operation.

\begin{tabular}{cccccc}
\hline $\begin{array}{c}\text { Time } \\
(\mathbf{d})\end{array}$ & $\begin{array}{c}\text { MLSS } \\
(\mathbf{g} / \mathbf{L})\end{array}$ & $\begin{array}{c}\text { MLVSS } \\
\text { (g/L) }\end{array}$ & $\begin{array}{c}\text { SOUR (mg O } / \mathbf{g} \\
\text { MLVSS h) }\end{array}$ & $\begin{array}{c}\text { SMP } \\
(\mathbf{m g} / \mathbf{L})\end{array}$ & $\begin{array}{c}\text { EPS (mg/g } \\
\text { MLVSS) }\end{array}$ \\
\hline $\mathbf{1}$ & 9.7 & 5.9 & 4.6 & 81 & 31 \\
$\mathbf{8}$ & 8.3 & 5.5 & 3.3 & 147 & 25 \\
$\mathbf{1 8}$ & 6.7 & 4.4 & 2.8 & 128 & 34 \\
$\mathbf{2 8}$ & 6.1 & 3.6 & 2.9 & 123 & 23 \\
$\mathbf{3 8}$ & 6.2 & 4.2 & 2.7 & 108 & 35 \\
$\mathbf{4 8}$ & 6.2 & 4.0 & 2.8 & 100 & 21 \\
$\mathbf{5 8}$ & 6.1 & 3.8 & 3.0 & 107 & 27 \\
\hline
\end{tabular}

Sludge response to the elevated bioreactor salinity also caused an increase in SMP concentration in the mixed liquor, especially within the first 8 days (i.e. the first OMBR-RO operating cycle). The increased SMP concentration was contributed by cell lysis, EPS release, and the production of unmetabolized and intermediate substances under the increased salinity (Reid et al., 2006). On the other hand, an increase in salinity could enhance the EPS 
solubility in the bioreactor (Laspidou and Rittmann, 2002). Thus, there was no significant variation in EPS concentration in the mixed liquor throughout the experiment (Table 1). This observation is consistent with that previously reported by Chen et al. (2014).

\section{Conclusion}

Results reported here show the potential of OMBR-RO with periodic MF extraction to simultaneously recover phosphorus and clean water from wastewater. Phosphorus was captured from the MF permeate, extracted periodically from OMBR mixed liquor, mainly in the form of amorphous calcium phosphates with phosphorus content of $15-20 \%$ at $\mathrm{pH} 10$. Periodic MF extraction also effectively controlled salinity build-up in the bioreactor, ensuring stable biological performance and increasing OMBR water production. Although OMBR-RO allowed for the recovery of high quality water, further investigation is required to address the build-up of organic matter and ammonia in the draw solution.

\section{Acknowledgements}

This research was supported under Australian Research Council's Discovery Project funding scheme (project DP140103864). Wenhai Luo would like to thank the Chinese Scholarship Council and the University of Wollongong for PhD scholarship support.

\section{References}

Achilli, A., Cath, T.Y., Marchand, E.A., Childress, A.E., 2009. The forward osmosis membrane bioreactor: a low fouling alternative to MBR processes. Desalination 239 (1), $10-21$.

Alturki, A.A., McDonald, J., Khan, S.J., Hai, F.I., Price, W.E., Nghiem, L.D., 2012. Performance of a novel osmotic membrane bioreactor (OMBR) system: flux stability and removal of trace organics. Bioresour. Technol. 113, 201-206.

Alvarez, R., Evans, L.A., Milham, P.J., Wilson, M.A., 2004. Effects of humic material on the precipitation of calcium phosphate. Geoderma 118 (3), 245-260.

Cao, X., Harris, W., 2008. Carbonate and magnesium interactive effect on calcium phosphate precipitation. Environ. Sci. Technol. 42 (2), 436-442.

Cath, T.Y., Hancock, N.T., Lundin, C.D., Hoppe-Jones, C., Drewes, J.E., 2010. A multibarrier osmotic dilution process for simultaneous desalination and purification of impaired water. J. Membr. Sci. 362 (1-2), 417-426. 
Chen, L., Gu, Y., Cao, C., Zhang, J., Ng, J.W., Tang, C., 2014. Performance of a submerged anaerobic membrane bioreactor with forward osmosis membrane for low-strength wastewater treatment. Water Res. 50, 114-123.

Conley, D.J., Paerl, H.W., Howarth, R.W., Boesch, D.F., Seitzinger, S.P., Havens, K.E., Lancelot, C., Likens, G.E., 2009. Controlling Eutrophication: nitrogen and phosphorus. Science 323 (5917), 1014-1015.

Cornelissen, E.R., Harmsen, D., Beerendonk, E.F., Qin, J.J., Oo, H., De Korte, K.F., Kappelhof, J.W.M.N., 2011. The innovative osmotic membrane bioreactor (OMBR) for reuse of wastewater. Water Sci. Technol. 63 (8), 1557-1565.

Cornelissen, E.R., Harmsen, D., de Korte, K.F., Ruiken, C.J., Qin, J.-J., Oo, H., Wessels, L. P., 2008. Membrane fouling and process performance of forward osmosis membranes on activated sludge. J. Membr. Sci. 319 (1-2), 158-168.

D’Haese, A., Le-Clech, P., Van Nevel, S., Verbeken, K., Cornelissen, E.R., Khan, S.J., Verliefde, A.R.D., 2013. Trace organic solutes in closed-loop forward osmosis applications: influence of membrane fouling and modeling of solute build-up. Water Res. 47 (14), 5232-5244.

Doyle, J.D., Oldring, K., Churchley, J., Parsons, S.A., 2002. Struvite formation and the fouling propensity of different materials. Water Res. 36, 3971-3978.

Dubois, M., Gilles, K.A., Hamilton, J.K., Rebers, P.A., Smith, F., 1956. Colorimetric method for determination of sugars and related substances. Anal. Chem. 28 (3), 350-356.

Hancock, N.T., Cath, T.Y., 2009. Solute coupled diffusion in osmotically driven membrane processes. Environ. Sci. Technol. 43 (17), 6769-6775.

Holloway, R.W., Childress, A.E., Dennett, K.E., Cath, T.Y., 2007. Forward osmosis for concentration of anaerobic digester centrate. Water Res. 41 (17), 4005-4014.

Holloway, R.W., Wait, A.S., Da Silva, A.F., Herron, J., Schutter, M.D., Lampi, K., Cath, T. Y., 2015. Long-term pilot scale investigation of novel hybrid ultrafiltration osmotic membrane bioreactors. Desalination 363, 64.

Jang, D., Hwang, Y., Shin, H., Lee, W., 2013. Effects of salinity on the characteristics of biomass and membrane fouling in membrane bioreactors. Bioresour. Technol. 141, 50-56.

Laspidou, C.S., Rittmann, B.E., 2002. A unified theory for extracellular polymeric substances, soluble microbial products, and active and inert biomass. Water Res. 36 (11), 2711-2720.

Lay, W.C.L., Liu, Y., Fane, A.G., 2010. Impacts of salinity on the performance of high retention membrane bioreactors for water reclamation: a review. Water Res. 44 (1), 21-40.

Lowry, O.H., Rosebrough, N.J., Farr, A.L., Randall, R.J., 1951. Protein measurement with the Folin phenol reagent. J. Biol. Chem. 193 (1), 265-275. 
Luo, W., Hai, F.I., Price, W.E., Guo, W., Ngo, H.H., Yamamoto, K., Nghiem, L.D., 2014. High retention membrane bioreactors: challenges and opportunities. Bioresour. Technol. $167,539-546$.

Nawaz, M.S., Gadelha, G., Khan, S.J., Hankins, N., 2013. Microbial toxicity effects of reverse transported draw solute in the forward osmosis membrane bioreactor (FO-MBR). J. Membr. Sci. 429, 323-329.

Nguyen, N.C., Chen, S.S., Nguyen, H.T., Ngo, H.H., Guo, W., Hao, C.W., Lin, P.H., 2015. Applicability of a novel osmotic membrane bioreactor using a specific draw solution in wastewater treatment. Sci. Total Environ. 518-519, 586-594.

Qiu, G., Law, Y.M., Das, S., Ting, Y.P., 2015. Direct and complete phosphorus recovery from municipal wastewater using a hybrid microfiltration-forward osmosis membrane bioreactor process with seawater brine as draw solution. Environ. Sci. Technol. 49 (10), 6156.

Qiu, G.L., Ting, Y.P., 2014. Direct phosphorus recovery from municipal wastewater via osmotic membrane bioreactor (OMBR) for wastewater treatment. Bioresour. Technol. $170,221-229$.

Reddy, K.R., DeLaune, D.R., 2008. Biogeochemistry of Wetlands: Science and Applications. CRC Press, Taylor \& Francis Group, Florida, ISBN: 9781566706780.

Reid, E., Liu, X., Judd, S.J., 2006. Effect of high salinity on activated sludge characteristics and membrane permeability in an immersed membrane bioreactor. J. Membr. Sci. 283, $164-171$.

Song, Y., Hahn, H.H., Hoffmann, E., 2002. Effects of solution conditions on the precipitation of phosphate for recovery: a thermodynamic evaluation. Chemosphere 48 (10), 10291034.

Tadkaew, N., Sivakumar, M., Khan, S.J., McDonald, J.A., Nghiem, L.D., 2010. Effect of mixed liquor $\mathrm{pH}$ on the removal of trace organic contaminants in a membrane bioreactor. Bioresour. Technol. 101 (5), 1494-1500.

Wang, X.H., Yuan, B., Chen, Y., Li, X.F., Ren, Y.P., 2014. Integration of micro-filtration into osmotic membrane bioreactors to prevent salinity build-up. Bioresour. Technol. 167, $116-123$.

Xie, M., Nghiem, L.D., Price, W.E., Elimelech, M., 2013. A forward osmosis membrane distillation hybrid process for direct sewer mining: system performance and limitations. Environ. Sci. Technol. 47 (23), 13486-13493.

Xie, M., Price, W.E., Nghiem, L.D., 2012. Rejection of pharmaceutically active compounds by forward osmosis: role of solution $\mathrm{pH}$ and membrane orientation. Sep. Purif. Technol. 93, 107-114. 
Xu, K., Wang, C., Liu, H., Qian, Y., 2011. Simultaneous removal of phosphorus and potassium from synthetic urine through the precipitation of magnesium potassium phosphate hexahydrate. Chemosphere 84 (2), 207-212.

Yap, W.J., Zhang, J., Lay, W.C.L., Cao, B., Fane, A.G., Liu, Y., 2012. State of the art of osmotic membrane bioreactors for water reclamation. Bioresour. Technol. 122, 217-222.

Zhang, X., Bishop, P.L., Kinkle, B.K., 1999. Comparison of extraction methods for quantifying extracellular polymers in biofilms. Water Sci. Technol. 39 (7), 211-218.

Zuthi, M.F.R., Guo, W.S., Ngo, H.H., Nghiem, L.D., Hai, F.I., 2013. Enhanced biological phosphorus removal and its modeling for the activated sludge and membrane bioreactor processes. Bioresour. Technol. 139, 363-374. 